\title{
REFLEXÕES SOBRE A FORMAÇÃO TÉCNICA, CIENTÍFICA E HUMANÍSTICA NO ENSINO DE 2 GRAU TÉCNICO PROFISSIONALIZANTE A PARTIR DA LEI DECRETO $5.692 / 71$
}

\author{
A. M. F. COSTA* e J. M. NASCIMENTO \\ Instituto Federal de Educação, Ciência e Tecnologia do Rio Grande do Norte \\ costa.max@ig.com.br
}

Artigo submetido em outubro/2013 e aceito em dezembro/2013

DOI: 10.15628/rbept.2013.3559

\section{RESUMO}

O presente artigo realiza reflexões sobre o tipo de formação técnica, científica e humanística proposta para o Ensino de 2ㅇ Grau Técnico Profissionalizante durante os anos 1970/80 no Brasil. Tem por objetivo colocar em questão se as práticas pedagógicas do projeto de ensino tecnicista se configuravam ação integradora para a formação do homem para o mundo do trabalho e para a ciência. Para tanto, realizou-se pesquisa em referenciais bibliográficos da Educação e da Educação Profissional, bem como o estudo da legislação educacional, com destaque para a Lei Decreto $\mathrm{n}-5.692$ de 11 de agosto de 1971. O estudo discute aspectos importantes como a aplicação da legislação educacional 5.692/71, o modelo de currículo e as práticas pedagógica implementadas naquela época no técnico profissionalizante.

PALAVRAS-CHAVE: Ensino Técnico Profissionalizante, Educação, Práticas Integradoras, Lei 5.692/71.

\section{REFLECTIONS ON TRAINING TECHNICAL, SCIENTIFIC AND HUMANISTIC IN EDUCATION LEVEL VOCATIONAL TECHNICAL FROM DECREE LEGISLATION NUMBER 5.692/71}

\begin{abstract}
This article presents reflections on the type of technical training, scientific and humanistic proposal for the Education of Grade 2 Technical College during the years 1970-80 in Brazil. It aims to put into question the pedagogical practices of technicist educational project they configured integrator action for the formation of man to the world of work and science. Therefore, it held
\end{abstract}

research in bibliographic references of Education and Vocational Education, and the study of educational legislation, especially the Decree Law number 5.692 of august 11,1971 . The study discusses important aspects such as enforcement educational 5.692/71, the model curriculum and pedagogical practices implemented at the time the professional technician.

KEYWORDS: Technical Vocational Education, Education, Integrators practices, Legislation 5.692/71. 


\section{INTRODUÇÃO}

Refletir sobre o diálogo entre a formação técnica, cientifica e humanística no ensino técnico profissionalizante de 2o Grau a partir da Lei Decreto no 5.692 de 11 de agosto de 1971 foi à motivação desse estudo bibliográfico e documental que se organiza a fim de compreender analiticamente o contexto histórico da década de 1970, da aplicação dessa legislação educacional nas escolas públicas do Brasil, bem como do currículo e das próprias práticas pedagógicas implementadas pelos docentes que atuavam naquela época, no denominado ensino técnico profissionalizante de 20 Grau. O texto ainda tenta refletir se existia de fato um esforço dos professores para realizar uma formação educacional integradora conforme recomendação presente na redação da Lei Decreto 5.692/71.

Durante os anos de 1970, o Brasil vivia sob a égide do regime militar e a educação passava por uma reformulação para atender aos interesses econômicos da classe dominante, aqueles que representavam o capitalismo (a burguesia). Estava em curso uma reforma na legislação educacional que promovia mudanças no ensino de 1 e e 2 음 Graus, para organizar a educação de nível médio como profissionalizante nos estabelecimentos de ensino do Brasil.

A obrigatoriedade do ensino de 20 Grau em se tornar profissionalizante no sistema de ensino da rede pública estadual gerou entre os profissionais da educação uma polêmica. $O$ fato suscitou debates sobre a nova perspectiva de formar sujeitos no 20 Grau com o perfil profissionalizante, iniciativa justificada pela crescente demanda das classes populares a esse tipo de ensino.

O Brasil nessa década vivenciava o período da industrialização, ou seja, do desenvolvimento industrial e para tanto era necessário mão de obra especializada e qualificada, então as escolas de 2ㅇ Grau deveriam se preocupar em formar técnicos de nível médio profissionalizante para satisfazer as expectativas do contexto social e econômica que vivia o país.

A premissa existia para as escolas que ofertavam o ensino de 20 Grau no Brasil, deveriam seguir as normativas da Lei Decreto 5.692/71, no sentido de implantar o ensino técnico profissionalizante, mas a obrigatoriedade só recaiu sobre o sistema de ensino público. A formação técnica profissionalizante não tinha a intenção de encaminhar o sujeito para a vida acadêmica e sim para o mercado de trabalho, de modo que "[...] as escolas privadas continuavam, em sua absoluta maioria, com os currículos propedêuticos voltados para as ciências, letras e artes visando 0 atendimento às elites" (BRASIL, 2007, p.14-15).

Mesmo sendo obrigatória a aplicação da Lei Decreto 5.692/71 foi resistida por parte de alguns estabelecimentos de ensino de 20 Grau. O que dificultou a implantação por completo dessa normativa nas escolas foi à falta de infraestrutura e orientação pedagógica sobre a proposta. Essa ação das escolas públicas de 2o Grau deu-se em:

Primeiro lugar, porque a concepção curricular que emanava da Lei empobrecia a formação geral do estudante em favor de uma profissionalização instrumental para o "mercado de trabalho", sob a alegação da importância da relação entre teoria e prática para a formação integral do cidadão (BRASIL, 2007, p.15).

A citação demonstra que a Lei 5.692/71 tinha em seu texto a intenção de integrar teoria e 
prática com o objetivo de formar o cidadão de maneira integral. O que diz essa lei sobre esse tipo de formação? A Lei Decreto 5.692/71 adverte em seu artigo1 que:

O ensino de 1 e e 20 Graus tem por objetivo geral proporcionar ao educando a formação necessária ao desenvolvimento de suas potencialidades como elemento de auto-realização, qualificação para o trabalho e preparo para o exercício consciente da cidadania.

O texto da Lei Decreto 5.692/71 propõe a superação da dualidade entre duas escolas: a que preparava para a vida e a que adestrava para o campo do trabalho. No entanto, essa Lei promoveu a união do trabalho intelectual (ciência, tecnologia e humanidades) e trabalho manual, tornando a escola única? Não havendo mais uma escola de habilitação comercial, agrícola ou normal, a escola de 2ํ Grau alargou as possibilidades de habilitação de técnicos, sob a crença do "milagre brasileiro", no cerne das políticas desenvolvimentistas do governo militar.

Bremer e Kuenzer (2012) nos advertem sobre o perigo da escola unidirecional, que prepara apenas para o mercado de trabalho e especificamente para o operariado nas indústrias:

Não queremos preparar mão de obra para a indústria. Queremos preparar o homem. O homem é mente e mãos: portanto se não educo com as mãos ele fica aleijado. É nesse sentido que nossas gerações estão saindo da escola todas intelectualistas. Vários fatores da inteligência não se desenvolvem se estiolam porque não (são) cultivados em idade própria, de 14 a 18 anos. Era este o sentido da educação para o trabalho.

A Lei Decreto 5.692/71 afirma que o ensino de 20 Grau objetivava formar o cidadão para o trabalho e para exercer sua cidadania, mas o que se observava era o "adestramento do estudante" com vistas ao mercado de trabalho (FRIGOTTO, 2010, p. 38). Nesse sentido, os alunos do ensino técnico profissionalizante provinham das classes populares e eram vistos como operários em formação para acrescer um exército de reserva.

Foi nesse momento que se consolida a tendência pedagógica tecnicista. Contexto em que o aluno era submetido a um processo rigoroso de controle do comportamento, com o propósito de levá-lo a atingir objetivos previamente estabelecidos, ou seja, nessa ideia de educação não havia preocupação com o processo cognitivo do aluno, mas apenas com o produto desejado. $\mathrm{O}$ que se buscava era "objetividade, produtividade e eficiência educacional", como afirma Saviani (1984). Nessa perspectiva de educação havia uma pseudo visão de neutralidade da escola, que deveria funcionar como se fosse uma empresa e inclusive o educador era visto como um instrutor que era fiscalizado pela figura do supervisor (a) educacional.

Conforme os preceitos dessa tendência de educação brasileira, o papel da escola era formar os indivíduos para o mercado de trabalho, sob as exigências impostas pelo modelo políticoeconômico capitalista, pois a sociedade industrial e tecnológica se consolidava no Brasil. Ainda vale apontar que os conteúdos ministrados nas escolas brasileiras eram baseados nos "princípios científicos", sistematizados em manuais e módulos de autoinstrução, que visavam objetivos e habilidades que levariam supostamente à competência técnica numa determinada área de atuação. O material didático se restringia aos estudos dirigidos ou programados, baseados na doutrina behaviorista que visava o adestramento de comportamentos.

A concepção de ensino proposta pela legislação educacional da Lei Decreto 5.692/71 
propunha um "pragmatismo" pedagógico, que se tornava perfil das escolas de ensino técnico profissionalizante, como no caso da principal escola desse tipo de formação em Natal, Rio Grande do Norte, durante os anos 1970 e 1980, a Escola Estadual Professor Anísio Teixeira, que nesse tempo formava uma mão de obra técnica especializada totalmente voltada para atender as necessidades do comércio da cidade de Natal, com a profissionalização de mão de obra nas áreas de administração e de contabilidade.

Formar estudantes nos cursos técnicos profissionalizantes de 2ㅇ Grau nos anos de 1970 e 1980 no cenário da Escola Estadual Professor Anísio Teixeira era a pura materialização do pensamento imposto pela Lei Decreto 5.692/71, visto que a maioria dos estudantes que ali eram treinados ou adestrados se inseria no mercado de trabalho. Esse fato justifica ainda mais o ideal da classe capitalista, que era formar mão de obra qualificada e barata para enriquecer o Brasil que se encontrava em pleno processo de industrialização e desenvolvimento econômico.

Nota-se que a formação do estudante da Escola Estadual Anísio Teixeira ficava a desejar e a sua inserção em um curso de nível superior era muito remota, pois o ser humano nesse modelo de escola técnica profissionalizante de $2 \stackrel{\circ}{\circ}$ Grau era formado com base no pensamento da tendência tecnicista ou tecnicismo.

É tanto que as práticas de ensino da Escola Estadual Anísio Teixeira nos anos de 1970 e 1980 eram permeadas por oficinas de mecanografia e visitas técnicas as empresas e lojas comerciais visando sempre o treino de técnicas para aplicação nesses espaços, não se aceitava jamais o erro dessas técnicas e nem o uso incorreto de equipamentos/máquinas disponíveis nesses locais.

As disciplinas ofertadas nesse modelo de ensino eram totalmente voltadas para a instrumentalização, no primeiro ano do 20 Grau técnico profissionalizante o estudante tinha contato com os componentes curriculares da base geral, tais como: Língua Portuguesa, Matemática, Educação Artística, Geografia, História, Língua Estrangeira, Educação Física, Química, Biologia e Física.

No segundo e terceiro ano do curso conforme a área escolhida o aluno estudaria disciplinas de instrumentalização: Administração, Contabilidade, Direito comercial, administrativo e trabalhista, Economia, Mecanografia, Estatística, Matemática Financeira, dentre outras.

Para melhor compreensão desse modelo de formação técnica profissionalizante de 2ㅇ Grau construiu-se o quadro que segue como ilustração:

Quadro 01: Resumo do Ensino Técnico Profissionalizante na Lei Decreto 5.692/71

\begin{tabular}{|c|c|}
\hline Década & 1970 e 1980. \\
\hline Contexto econômico & Capitalista. \\
\hline Segmento de Ensino & 20 Grau Técnico Profissionalizante. \\
\hline $\begin{array}{c}\text { Objetivos do Ensino Técnico } \\
\text { Profissionalizante de 2o Grau }\end{array}$ & Formar mão de obra qualificada para o mercado de trabalho. \\
\hline Classe Social & Filhos do proletariado (classe trabalhadora). \\
\hline Tendência Pedagógica & Tradicional tecnicista. \\
\hline Currículo & Voltado para o adestramento ou treinamento para a profissão escolhida. \\
\hline Conteúdos & Princípios científicos entendidos como manuais e módulos de autoinstrução. \\
\hline Material Instrumental & Manuais, livros didáticos e apostilas. \\
\hline Práticas Pedagógicas & Focada nos resultados finais, buscando atingir a objetividade, produtividade e \\
eficiência.
\end{tabular}

Fonte: Resumo construído pelo autor. 
Esse quadro resumo do ensino técnico profissionalizante de $2 \circ$ Grau demonstra claramente como as práticas pedagógicas e o modelo político econômico e cultural influenciou o tipo de educação ofertado para a classe trabalhadora, na qual a única preocupação era com a técnica para fazer uso na indústria, no comércio e nas empresas. Essa era a marca do modelo pedagógico tecnicista ou do tecnicismo.

O educador Paulo Freire (1996) apresentou severas críticas ao tecnicismo no Brasil, conceituando-o como sendo formação limitadora quando se preocupa apenas com o treino técnico científico do discente. A concepção de Freire (1996) amplia essa perspectiva e diz que a formação dos sujeitos deve ser para a vida e ir além da preparação técnica e científica, inclusive não ser uma educação bancaria, aquela em que o professor deposita inúmeras informações no cérebro do estudante e este só faz memorizar para usar apenas em uma atividade fim, não servindo para aplicar nas várias situações da vida social.

Quando Freire (1996) adverte que a formação do estudante do ensino técnico profissional deveria ir além da instrução técnica e científica, ele defendia que o discente deveria ser formado para lidar com os vários aspectos da vida, do mundo do trabalho, da ciência, da cultura e da tecnologia. Com base nessas ideias, levanta-se a defesa da proposta de ensino pautada no ideal de currículo integrado a fim de fornecer uma sólida formação científica, tecnológica, cultural e ética, assim como advoga Machado (2010).

Currículos integrados são oportunidades riquíssimas para explorar as potencialidades multidimensionais da educação, para superar a visão utilitarista do ensino, para desenvolver as capacidades de pensar, sentir e agir dos alunos, para realizar o objetivo da educação integral (MACHADO, 2010, p.92).

Percebe-se após definir o que são currículos integrados, que nessa época o pensamento educacional ou o modelo de ensino técnico de 2ㅇ Grau ofertado conforme a Lei Decreto 5.692/71 não era a mesma proposta defendida por Machado (2010) até porque o formato de currículo integrado proposto pela autora é de certa maneira uma possibilidade de integração entre as finalidades e os objetivos da escola à prática pedagógica, tornando-os efetivamente concreto e que em hipótese alguma se destina a adestrar o estudante.

Diante dessa discussão é interessante deixar claro que a proposta pedagógica da tendência tecnicista, que vigorava nos anos 1970 e 1980 era unilateral, apenas se preocupava com a formação técnica, divergindo da proposta do currículo integrado atual apresentada pela professora Dra. Lucília Machado, que busca considerar as muitas dimensões da vida dos alunos e das práticas sociais em que estão incluídos, tentando entendê-los como sujeitos implicados no seu próprio processo de formação e ainda contribuir para a sua libertação, transformando em um ser crítico.

Ao pensar as práticas pedagógicas atuais a partir das concepções de Machado (2010) e Freire (1996) é salutar destacar que na contemporaneidade não se deve pensar a educação como sendo algo dissociado do todo, ou seja, não se deve separar as partes do todo, mas tratá-las como uma totalidade social com suas múltiplas mediações históricas que concretizam os processos educativos, como bem frisou Ciavatta (2005).

Fazer dialogar a formação técnica, humanística e científica é de certa maneira uma tentativa de integrar os conhecimentos práticos aos teóricos como sendo complementares, 
mesmo sendo paradoxalmente diferentes, mas estes são passíveis de uma religação, como defende Edgar Morin (2002) em sua teoria da complexidade. Mas o que é uma formação educacional integradora?

A formação educacional integradora é aquela em que os seus objetivos se destinam a tornar interdependentes áreas diversificadas de conhecimentos, sendo assim a escola formaria o educando para a vida, permeando os espaços do mundo do trabalho e do fazer científico. O que na verdade não aconteceu no ensino técnico profissionalizante de 20 Grau regido pela Lei Decreto 5.692/71, diz-se isso porque seus fins era apenas a formação técnica do estudante.

A proposta do ensino de 2 ㅇ Grau profissionalizante objetivava formar mão de obra rápida e barata, por isso estava distante de querer unir os conhecimentos do currículo propedêutico e instrumental, rompendo-se parcialmente com a escola que dividia o ensino para os ricos (propedêutico) e para os pobres (instrumental).

Moura (2010) chama atenção quando diz que não basta apenas dá acesso à Educação Básica a classe popular, mas é bom que se garanta a aquisição de conhecimento para esse povo.

Quando se fala em efetivar a garantia da aprendizagem da classe menos favorecida brasileira significa fazer com que essa classe integre cidadãos críticos, de modo que tenham consciência que são detentores de direitos e de deveres e não somente reprodutores desses ideais.

Diante desse movimento de discussão sobre aplicação da Lei Decreto 5.692 de 11 de agosto de 1971, do modelo de currículo e das práticas pedagógicas do ensino técnico profissionalizante de 20 Grau e se de fato existia por parte dos professores uma preocupação na integralização do ensino, chega-se a conclusão que a educação técnica profissionalizante, normatizada pela Lei Decreto 5.692/71, era um modelo educacional que deveria servir como obrigatório para as escolas públicas e este se destinava apenas a instrumentalizar os sujeitos para contribuírem com o fortalecimento do capitalismo no Brasil e, além disso, reafirmar que existiam duas escolas, uma para os filhos da classe trabalhadora e outra para os filhos da classe burguesa.

\section{REFERÊNCIAS}

1. ARROYO, M. Trabalho, Educação e Teoria Pedagógica. In: FRIGOTTO, G. (Org.). Educação e Crise do Trabalho. Perspectivas de final de século. 2. ed. Petrópolis: Editora Vozes, 1998.

2. BRASIL. Ministério da Educação. Secretaria de Educação Profissional e Tecnológica. Educação Profissional Técnica de Nível Médio Integrada ao Ensino Médio. Brasília: MEC, 2007.

3. Ministério da Educação. Educação Profissional e Tecnológica: legislação básica-rede federal/secretaria de educação profissional e tecnológica. 7. ed. Brasília: MEC; SETEC, 2008.

4. BRASIL. Lei n. 5.692, de 11 de Agosto de 1971. Disponível em: http://www.planalto.gov.br/c civil_03/leis/I5692.htm>. Acesso em 24 de Mai. 2015.

5. L_ Lei n. 9.394, de 20 de Dezembro de 1996. Disponível em: http://www.planalto.gov.br/ccivil_03/leis/I9394.htm>. Acesso em 24 de Mai. 2015.

6. BREMER, Maria Aparecida de Souza; KUENZER, Acácia Zeneida. ENSINO MÉDIO INTEGRADO: UMA HISTÓRIA DE CONTRADIÇÕES. IX ANPED SUL. Seminário de Pesquisa em Educação da Região Sul. 2012. Disponível em: < http://www.ucs.br/etc/conferencias/index.php/anpedsul/ 9anpedsul/paper/viewFile/2217/208>. Acesso em 12 de mai. 2015. 
7. CIAVATTA, Maria; RAMOS, Marise. A "era das diretrizes": a disputa pelo projeto de educação dos mais pobres. Rev. Bras. Educ. [online]. 2012, vol.17, n.49, pp. 11-37. ISSN 1413-2478. Disponível em: <http://dx.doi.org/10.1590/S1413-24782012000100002>. Acesso em: 20 de abr. 2015.

8.

A Formação Integral: a escola e o trabalho como lugares de memória e de identidade. In: FRIGOTTO, G.; CIAVATTA, M.; RAMOS, M. N. Ensino Médio Integrado: comparação e contradições. São Paulo: Cortez, 2005, p. 85-105.

9. CUNHA, Luiz Antônio. O ensino profissional na irradiação do industrialismo. São Paulo: Unesp, 2005.

10. FREIRE, Paulo. Pedagogia da Autonomia: saberes necessários à prática pedagógica. São Paulo: Paz e Terra, 1996.

11. FRIGOTTO, Gaudêncio. A Relação da Educação Profissional e Tecnológica com a Universalização da Educação Básica. In: MOLL, Jaqueline. Educação Profissional e Tecnológica no Brasil Contemporâneo: desafios, tensões e possibilidades. Porto Alegre: Artmed, 2010, p. 25-40.

12. MACHADO, L. Ensino Médio e Técnico com Currículos Integrados: proposta de ação didática para uma relação não fantasiosa. In: MOLL, Jaqueline. Educação Profissional e Tecnológica no Brasil Contemporâneo: desafios, tensões e possibilidades. Porto Alegre: Artmed, 2010, p. 8095.

13. MOLL, Jaqueline (Org.). Educação Profissional e Tecnológica no Brasil Contemporâneo: desafios, tensões e possibilidades. Porto Alegre: Artmed, 2010.

14. MORIN, Edgar. Os sete saberes necessários à educação do futuro. 5. ed. São Paulo: Cortez, 2002.

15. MOURA, D. H. Ensino Médio e Educação Profissional: dualidade histórica e possibilidade de integração. In: MOLL, Jaqueline. Educação Profissional e Tecnológica no Brasil Contemporâneo: desafios, tensões e possibilidades. Porto Alegre: Artmed, 2010, p. 58-79.

16. RAMOS, Marise. Ensino Médio Integrado: ciência, trabalho e cultura na relação entre educação profissional e educação técnica. In: MOLL, Jaqueline. Educação Profissional e Tecnológica no Brasil Contemporâneo: desafios, tensões e possibilidades. Porto Alegre: Artmed, 2010, p. 42-57.

17. SAVIANI, Dermeval. História das Ideias Pedagógicas no Brasil. 3. ed. Campinas-SP: Autores Associados, 2010.

18.

Escola e democracia: teorias da educação, curvatura da vara, onze teses sobre educação e política. 5. ed. São Paulo: Cortez/Autores Associados, 1984. (Coleção Polêmicas do nosso tempo, 5).

19. VIAMONTE, Perola Fátima Valente Simpson. Ensino Profissionalizante e Ensino Médio: Novas análises a partir da LDB 9394/96. Revista Educação em Perspectiva, Viçosa, v.2, n.1, jan./jun, 2011. 